NBER WORKING PAPER SERIES

\title{
WHAT JOBS ARE BEING DONE AT HOME DURING THE COVID-19 CRISIS? EVIDENCE FROM FIRM-LEVEL SURVEYS
}

\author{
Alexander W. Bartik \\ Zoe B. Cullen \\ Edward L. Glaeser \\ Michael Luca \\ Christopher T. Stanton \\ Working Paper 27422 \\ http://www.nber.org/papers/w27422 \\ NATIONAL BUREAU OF ECONOMIC RESEARCH \\ 1050 Massachusetts Avenue \\ Cambridge, MA 02138 \\ June 2020
}

We thank Karen Mills for connecting us to Alignable and the Alignable founders for providing data. Mateo Arbelaez provided excellent research assistance. Research funding was provided by Harvard Business School. The views expressed herein are those of the authors and do not necessarily reflect the views of the National Bureau of Economic Research.

At least one co-author has disclosed a financial relationship of potential relevance for this research. Further information is available online at http://www.nber.org/papers/w27422.ack

NBER working papers are circulated for discussion and comment purposes. They have not been peerreviewed or been subject to the review by the NBER Board of Directors that accompanies official NBER publications.

(C) 2020 by Alexander W. Bartik, Zoe B. Cullen, Edward L. Glaeser, Michael Luca, and Christopher T. Stanton. All rights reserved. Short sections of text, not to exceed two paragraphs, may be quoted without explicit permission provided that full credit, including () notice, is given to the source. 
What Jobs are Being Done at Home During the Covid-19 Crisis? Evidence from Firm-Level Surveys

Alexander W. Bartik, Zoe B. Cullen, Edward L. Glaeser, Michael Luca, and Christopher T.

Stanton

NBER Working Paper No. 27422

June 2020

JEL No. J01,J24,M5,O3

\section{ABSTRACT}

The threat of COVID-19 has increased the health risks of going to an office or factory, leading more workers to do their jobs remotely. In this paper, we provide results from firm surveys on both small and large businesses on the prevalence and productivity of remote work, and expectations about the persistence of remote work once the COVID-19 crisis ends. We present four main findings. First, while overall levels of remote work are high, there is considerable variation across industries. The Dingel and Neiman (2020) measure of suitability for remote work does a remarkably good job of predicting the industry level patterns of remote work - highlighting the challenge of moving many industries to remote work. Second, remote work is much more common in industries with better educated and better paid workers. Third, in our larger survey, employers think that there has been less productivity loss from remote working in better educated and higher paid industries. Fourth, more than one-third of firms that had employees switch to remote work believe that remote work will remain more common at their company even after the COVID-19 crisis ends.

Alexander W. Bartik

University of Illinois

1407 W. Gregory Road

214 David Kinley Hall

Urbana, IL 61821

abartik@illinois.edu

Zoe B. Cullen

Rock Center 210

Harvard Business School

60 N. Harvard

Boston, MA 02163

zcullen@hbs.edu

Edward L. Glaeser

Department of Economics

315A Littauer Center

Harvard University

Cambridge, MA 02138

and NBER

eglaeser@harvard.edu
Michael Luca

Harvard Business School

Soldiers Field

Boston, MA 02163

and NBER

mluca@hbs.edu

Christopher T. Stanton

210 Rock Center

Harvard University

Harvard Business School

Boston, MA 02163

and NBER

christopher.t.stanton@gmail.com 


\section{Introduction}

The COVID-19 pandemic left companies in some industries, such as meatpacking, with a choice between stopping production altogether or taking on the health risk of continuing business as usual. In other industries, like accounting, there was a third option: having more employees work from home. In this paper, we use two firm level surveys to shed light on remote work during the pandemic. We explore the extent of remote work - both overall and across industries, as well as the implications for productivity and inequality, and the extent to which remote work is likely to persist after the end of the pandemic.

To explore, we use two survey populations. Our first, larger survey population queries 1,770 leaders of small businesses who are part of the Alignable network. ${ }^{2}$ Eight weeks after the first survey, Alignable conducted a follow up survey to further probe remote work. We supplement this data with a survey of 70 business economists who are members of the National Association of Business Economists (NABE). The first Alignable survey and the NABE survey were conducted during March and April of 2020 (respectively), while much of the country was under stay-at-home restrictions. The Alignable survey's much larger size makes it our preferred source, but the NABE survey provides better coverage of larger employers. The surveys also asked slightly different questions, reflecting different respondent bases -- as Alignable respondents were generally owners or managers of small businesses, whereas NABE respondents generally work at larger firms and are not owners.

Overall, we observe high levels of remote work, which we define as working from home at least two days per week. In the Alignable network, 45 percent of firms report having any workers switch to working remotely during the COVID-19 pandemic. In the NABE survey, 50 percent of firms have more than one-fifth of their employees working remotely. The NABE firms seem to have more remote working, likely due to the fact that more of these firms are in white collar industries where remote working is easier.

To explore the cross-industry variation in remote work, we build on recent work by Dingel and Neiman (2020), in which they construct an industry level classification of remote work feasibility (i.e. an assessment of which jobs could plausibly be done at home $)^{3}$. This classification has now been influential both in research and in practice, and has been applied to multiple settings as a way to understand the potential for remote work across industries and in different countries (Saltiel 2020, Stratton 2020). Whereas they focus on the potential to work from home, we can observe the extent to which feasibility constraints bind in practice, and whether they predict the observed variation in remote work. Applying this classification to OES data from the BLS, they find that roughly $37 \%$ of jobs could potentially be done entirely from home across the full composition of US firms. Applying their measure to the small businesses responding to our Alignable survey, we find that roughly 27 to 31 percent of employees in the Alignable sample could feasibly work remotely. The gap reflects the

2 Previous work has assessed the representativeness of this survey sample, and found it to provide broad coverage across industries and geographies, and to roughly match the distribution of Census firms on firm size and location (Bartik et al., 2020, Balla-Elliott et al., 2020).

${ }^{3}$ They do this using pre-COVID-19 O*NET data, and cross validate with a hand coding of occupations. 
composition of our sample, which focuses on small businesses. Approximately 60 percent of employees at firms responding to the NABE survey (due to their larger size and industry composition) are able to telecommute.

We also find that the Dingel and Neiman classification of work from home capacity is a strong predictor of industry level variation in remote work during the pandemic. Figure 1 shows a 33 percent correlation across industries between the potential for remote work identified by Dingel and Neiman (2020) and the actual prevalence of remote work in the Alignable survey. Figure 2 shows a 29 percent correlation between the Dingel and Neiman (2020) measure and the prevalence of remote work across industries in the NABE survey. We have a very limited number of industries in the NABE sample, but even so both correlations are statistically significant.

The uneven ability to work from home raises concerns about inequality as well. Merging our survey with pre-crisis industry-level characteristics from the American Community Survey, we find remote work during the crisis is more common in highly educated industries. In the most educated quartile of industries, 64 percent of firms had some workers switch to remote work. In the least educated quartile of industries, only 36 percent of firms had any workers switch to remote work. In the NABE survey, there is also a statistically significant relationship between education and the share of workers engaged in remote work. This suggests that less educated workers may tend to face a starker choice between health risks and their jobs, whereas more educated workers are more likely to have - and take - the option to work from home.

Does the shift to remote work increase or decrease productivity? From both the NABE survey and a small set of respondents from the Alignable survey, we have some information about the productivity of remote workers. In the NABE survey, respondents chose broad categories for remote worker productivity, such as above, below or equal to non-remote productivity. In the Alignable survey, we asked them to quantify productivity relative to pre-COVID non-remote levels. In both cases, we believe that these answers are often impressionistic, and may miss longer term productivity consequences of shifting to remote work.

The NABE respondents were generally positive about remote working productivity. A majority believed that remote working did not involve any productivity loss and 28 percent thought that workers had become more productive through remote working. The Alignable respondents were less optimistic, reporting an average productivity change of -0.198 (on a -1 to 1 scale, with 0 representing no change). However, this average masks significant heterogeneity, as 29 percent of Alignable respondents thought that workers had become more productive by staying home.

In the Alignable survey, productivity assessments for remote workers are positively correlated with the Dingel and Neiman (2020) measure of suitability of remote work, which provides further support for the validity of their measure. Remote work productivity is also correlated with both education and the share of employees who worked from home pre-COVID. Given the small sample in the NABE survey, there are few significant correlations of remote work productivity in the NABE survey. 
Finally, we looked at firms' expectations about whether the increase in remote working will continue into the future after the COVID-19 crisis has passed. In the NABE survey, we find that 36 percent of respondents believe that more than 40 percent of workers who had switched to remote work during the COVID-19 crisis would continue working remotely after the crisis ends. The Alignable survey results were quite similar, and 40 percent of firms thought that 40 percent of more of their workers that switched to remote work during the COVID-19 crisis would continue working remotely after the crisis ends. If these projections prove true, this suggests a significant reduction in future demand for office space.

Overall, our findings shed light on remote work during the COVID crisis. For decades, there has been discussion of the potential rise of remote work, and the challenges to implementing broader adoption of remote work (Gasper and Glaeser 1998). Our results point both to the rapid shift to remote work during the COVID crisis, and the challenge that many industries have faced in the move to remote work. Using the Dingel and Neiman (2020) classification of feasibility of remote work, we find that feasibility constraints are an important predictor of which industries are able to successfully transition.

Prior research has also demonstrated the potential productivity gains from moving to remote work (Bloom et al 2015, Bloom, 2014) and the value employees place on being able to work remotely (Mas and Pallais 2017, 2020). Our results suggest that the gains are uneven - with many firms also becoming less productive as a result of the transition. This variation can also be predicted by an a priori classification of suitability for remote work. Nonetheless, our work also suggests that remote work is likely to remain at higher levels even after the crisis, and that the COVID crisis may have a persistent impact on the nature of work.

\section{Data Description}

In this section, we first describe the Alignable network survey, and then discuss the NABE survey. We then mention our sources of additional industry level data as well. As we discuss the sources, we will also mention the summary statistics contained in Table 1.

\section{The Alignable Network Survey}

Alignable < https://www.alignable.com> is the largest network and community of Small Business Owners in North America. We use two surveys that come from this universe. Questions about remote work were included in a first survey where Alignable members were directed to an external survey by Harvard Business School researchers. This survey was conducted in late March and early April and is described in Bartik, et al. (2020). The remote work questions came at the end of this survey and were asked of businesses that either had strictly more than 1 full time or strictly more than 1 part-time employees at the time of the survey. These questions received 2,181 total responses (out of 3,028 who met the conditions for these questions but dropped out of the survey). We drop 361 responses due to 
missing industry information and another 50 observations due to missing employment. This leaves 1,770 business owners in the sample.

We also use data from a survey conducted by Alignable, Inc from May 23 - May 28, 2020 to capture future projections about remote work. Several remote work questions were included at the end of this poll, which otherwise focused on businesses' operational status and recovery efforts. There are 1,060 responses in the universe based on response criteria, which for this survey entailed having greater than two current employees. After restricting to respondents with a known industry and employment information, we are left with 908 responses.

The online appendix discusses representativeness of the sample. There is broad coverage in the survey, so we point out areas where the survey and Census differ. The survey has fewer firms in Professional, Scientific and Technical Services ( $9.2 \%$ of the survey compared to $13.4 \%$ of Census firms) and Other Services $(11.6 \%$ versus $8.9 \%)$. The survey has more firms in Retail Trade $(10.7 \%$ in the Census versus $16 \%$ in the survey), Healthcare and Social Assistance (10.8\% versus 12.4\%), and Arts, Entertainment, and Recreation (2.2\% versus $9.2 \%$ ). Coverage across states is broad and conforms well with the Census of businesses, although the survey over-represents California and under-represents New York and Illinois.

\section{The National Association of Business Economists Survey}

The National Association of Business Economists (NABE) is a professional organization for business economists who mainly work in company settings. The questions we analyze were sent out as part of a quarterly survey of 492 private sector NABE members. The survey was run between April 13 and 16, 2020. About a quarter, or 124, economists responded, representing 118 firms. When more than one economist answered the survey for a particular firm, we take the average response by economists at the firm. A further 8 respondents did not report their firm. We dropped these respondents and also further restricted the sample to only firms that answer the main questions we focus on in the study, reducing our sample to 70 firms.

The firms in the NABE survey are predominantly larger, with almost 40 percent having more than 1000 employees, and over 50 percent having more than 100 employees. The firms span a broad set of industries, with about 50 percent primarily operating in the service sector, another 25 percent in

finance, insurance, and real-estate, about 15 percent in goods producing industries, and slightly more than 10 percent in transportation, utilities, warehouses, and communication.

\section{Other Data Resources}

Finally, we merge in data from the Census American Community Survey (ACS) for 2016-2017 at the 2-digit industry level. 


\section{Summary Statistics and General Patterns}

Table 1, Column 1, displays summary statistics for the Alignable sample collected in March/April. The average firm size was 14 employees in January 2020 (prior to COVID). At the time of the survey, these firms had an average of 3.6 months of cash on hand, with the median firm having 1 month of cash on hand. Employment at the sample firms declined by $15.9 \%$ from January to March/April. ${ }^{4}$

Owners were asked: "Relative to January 2020, have any of your employees transitioned to working remotely or working from home?" Those answering yes were then asked, "Compared to January 2020, how has remote work affected these employees' productivity?" The productivity question displayed a slider ranging from -100 to 100 . Above the slider, a label above -100 and -60 read "Much Less Productive." At 0 the label read "About the Same" and at 60 to 100 the label read "Much More Productive." To ease interpretation, we rescale this productivity measure to range between -1 and 1 .

Forty-five percent of the Alignable respondents reported that at least some workers transitioned to remote work since January. Our firm level results complement the measurement of remote working by Brynjolfsson et al. (2020), who use a Google survey to estimate employee level changes in remote work. They find that $34 \%$ of respondents reported working from home as of early April (conditional on reporting having been employed four weeks earlier).

We also have 653 responses to the question asking about productivity. The average productivity change is -0.198 on a -1 to 1 scale. Of the $65 \%$ of respondents who report strictly negative productivity changes, the average (median) reduction is $-0.43(-0.40)$. Of the $29 \%$ who expect a productivity change that is greater than 0 , the average (median) increase in productivity is $0.28(0.13) .5 .4 \%$ reported no difference.

What explains these differences? The final rows build in data from Dingel and Neiman (2020) on the ease of remote work. They construct these measures either via manual inspection or via O-NET questions that describe the occupational characteristics that enable remote work. They then take these two measures at the occupation level and compute industry level averages (the measures we use) by using Occupation Employment Statistics data to map occupation shares to industries.

To capture the intensity of remote work, the Alignable survey wave in May asked "What share of your workers (who did not work remotely prior to COVID-19) have started working remotely now?" Answers were bucketed in quintiles ranging from $0-20 \%$ to $80-100 \%$. Using the midpoint of the categories and taking averages over responses, $22.7 \%$ of the workforce was newly working remotely in the May survey. Approximately 77 percent of respondents chose the bottom quintile, or $0-20 \%$ for this question. About $1 / 3$ of the responses in this quintile would need to be non-zero for the distribution of responses to align with the March/April survey wave patterns in column 1. An example from the

\footnotetext{
4 This represents a smaller employment loss than the comparable figures in Bartik et al. (2020). The difference is explained by restricting to firms that did not completely reduce employment to 0 - that is, our sampling frame for assessing the extent of remote work conditions on firms that maintain employment.
} 
modal industry in our sample would be a retailer with a physical establishment moving only a subset of their employees into remote e-commerce jobs ${ }^{5}$

A different possibility is that the early indications of a shift to remote work at the beginning of the pandemic in column 1 had begun to subside as businesses started to reopen their regular operations toward the end of May, 2020. Still, there is significant heterogeneity in this sample from late May. The second most popular answer, chosen by $10.9 \%$ of respondents, is that $80-100 \%$ of employees were working remotely.

To investigate future projections, those who indicated that more than $20 \%$ of employees were remote received the question: "What share of your workers who started working remotely during COVID-19 do you think will continue to work remotely (at least 2 normal working days per week) once the COVID-19 crisis ends and other businesses and services reopen?" The survey continued to probe for reasons behind these choices; these questions are described in further detail in Section V.

\section{The Extent of Remote Work}

We now turn to the correlates of working remotely during the crisis. Panel A of Table 2 shows our results from the Alignable network survey from the March/April wave. Panel B shows results from the Alignable survey from the late May wave. Panel C shows results from the NABE survey conducted in April. We have 1,770 observations in the first Alignable survey, 908 in the second, and 70 in the NABE survey. Our regressions are clustered at the 2-digit NAICS industry level, and we have 16-18 industries represented in the Alignable survey and 12 industries in the NABE survey.

The first row in Table 2a shows the correlation between the Dingel and Neiman (2000) industry-level measure of suitability to work at home and whether the firm reports any employees switching to working from home. The coefficient has a t-statistic of almost ten, and eleven percent of the total variation in this variable at the firm level is explained by this industry-level measure. The strong link between the Dingel and Neiman (2000) measure of potential remote working and the actual level of remote working is shown in Figure 1. As 10 percent more of an industry's tasks are deemed suitable for working at home, the probability that a firm will have some workers switch to working at home increases by 7.1 percentage points.

The second row shows the correlation between working at home before the COVID crisis and switching to working at home now. Again, there is a strong positive correlation, and the coefficient is above four, which partially reflects the relatively low share of employees working from home before the COVID crisis. The industry with the greatest share of remote work pre-crisis is Professional, Scientific, and Technical Services, with 12\% of ACS employees reporting that they work from home. The across-industry average is $4.7 \%$. A firm in an industry which had five percent of its employees

\footnotetext{
${ }^{5}$ Retail trade increased by 18\% in May, after falling 15\% in April: https://www.census.gov/retail/index.html.
} 
working from home before the COVID crisis is 20 percent more likely to have some employees switching to working from home during the COVID crisis.

The third row shows the correlation with the share of workers in the industry that have at least a college degree. This variable has almost as much predictive power as the Dingel and Neiman (2020) measure, which reflects the extremely strong link between being a knowledge worker and being able to work from home. As the share of employees in an industry with a college degree increases by ten percentage points, the probability that the firm will have some employees switch to working at home increases by 9.4 percentage points. This correlation suggests that better educated workers often have the ability to continue working safely, while less educated workers often face a difficult choice between joblessness and risk of contagion.

The fourth column shows the correlation with the share of the industry that is female. There is a weak positive relationship between percent female in the industry and the switch to remote working. As the share of female workers in the industry increases by ten percentage points, the probability of having some employees switch to remote working increases by 1.7 percentage points. ${ }^{6}$

The fifth column shows the relationship between firm size and the switch to working from home. We do find that larger firms are more likely to have working from home, possibly because the question is about "any" workers switching to remote working, not about the share of workers who switch to remote work. This positive slope is driven by a discrete gap between the largest firms in this sample and the other firms. We find that 79 percent of firms with 100 or more employees in this sample have some workers switching to remote working, but 45 percent of firms with fewer than 100 employees have some workers switching to remote working.

In the sixth column, we include our two industry level variables and our one firm-level variable in a single regression. We find that the coefficient on the share of workers with a college degree increases in magnitude and remains significant. The coefficient on the share of workers who are female flips sign, suggesting that holding education constant, firms in industries with more women are less likely to switch to remote working during this period. The firm size coefficient becomes stronger.

In the seventh column, we include the Dingel and Neiman (2020) measure as well as these three firm and industry variables. Only firm size remains significant, but the share of workers with college degrees remains large in magnitude. This result means little, since the Dingel and Neiman (2020) is meant to predict, not to generate independent variation in the extent of working from home controlling for other variables.

The final regression includes the three firm and industry variables and the share of employees working from home before the crisis. In this case, all of the firm and industry variables remain significant, and the share female continues to have an unexpected negative sign. The share of employees that worked

\footnotetext{
${ }^{6}$ We have limited owner demographic data for a subset of the businesses (454). Forty-four percent of the male-owned businesses (or 180 out of 409) report that they have some remote work. One third out of the forty-five that we can identify as female owned have some remote work. In this limited sample, we find that female ownership is not associated with more remote working, but it is hard to draw conclusions from 45 female-owned businesses.
} 
remotely pre-crisis flips sign and loses significance. To us, these results suggest that current firm characteristics predict the switch to working from home during the crisis more than past practices, but since our past remote working variable is calculated at the industry level, it will only modestly capture actual experience with working from home for these particular firms.

Panel B of Table 2 switches to the May Alignable survey question about what share of employees have switched to working from home. As discussed above, respondents entered coarse ranges and we transformed these into percentages based on the midpoint of the range. We followed this procedure with the NABE results that follow, so that coefficients of Panel B and Panel C are comparable, whereas coefficients from Panel A capture extensive margin changes.

In the first regression, we estimate a coefficient of .28 on the Dingel and Neiman (2020) measure of suitability for remote work. The r-squared is somewhat lower than in Panel A, but the result remains strongly significant. As the share of work that is suitable for remote performance in an industry rises by ten percentage points, the share of workers that switched to working remotely in the industry increases by 2.8 percentage points. This coefficient may be less than one either because of measurement error in the explanatory variable, or because it takes time to switch some jobs to remote work.

The second regression shows that a ten percentage point increase in the share of employees in the industry that worked remotely before the COVID-19 crisis is associated with a 13.6 percentage point increase in the share of workers who switched to working remotely during the crisis. A coefficient greater than one suggests that this variable is also capturing the potential for remote work in the industry.

Columns (3) and (4) show that the education and gender facts shown in Panel (a) replicate using this different measure and over a larger time period. As the share of workers in the industry with a college degree increases by ten percentage points, the share of workers who switch to working remotely increases by 3.9 percentage points. As the share of workers in the industry who are women increases by ten percentage points, the share of workers who are remote increases by 1.7 percentage points.

Column (5) shows that there is no firm size effect. This finding supports the hypothesis that the firm size effect in Panel (a) reflects the fact that it is much easier to have a single worker switch to remote work when the firm has many more workers.

The last three regressions include different controls at once. The firm size variable is never significant. Education is significant in regressions (6) and (8), but not in regression (7) where we control for the Dingel and Neiman (2020) measure. The Dingel and Neiman (2020) variable remains similar in magnitude, but moves to the margins of statistical significance, largely because of the high correlation between this variable and education at the two-digit industry level. The share of workers who were remote before COVID-19 flips sign and becomes insignificant once we control for these other industry level variables.

In Table 2 Panel C, we turn to our NABE survey results. Our dependent variable is a continuous measure of the share of employees that are working from home, as in Panel (b). In the first column, 
we again find a strong positive relationship between actual remote working and the Dingel and Neiman (2000) measure. The coefficient is quite similar to the comparable coefficient in Panel (b). As the share of workers in the industry that are suitable for remote work increases by 10 percentage points, the actual share of remote workers in the firm increases 2.8 percentage points.

The second column includes the share of employees working from home before the COVID crisis. Again, the relationship is significant and the coefficient is both greater than one and quite similar to the panel (b) coefficient. As the share of employees working from home increases from zero to ten percentage points pre-COVID, the share of employees working from home during the crisis increases by 16 percentage points.

The third column shows the results for the share of the industry's workers with college degrees. The coefficient is positive and almost identical to the panel (b) coefficient, but only on the borderline of statistical significance. As the share of workers with a college degree in the industry increases by ten percentage points, the share of employees working from home during the crisis increases by 3.7 percentage points. Again, this suggests that if the COVID crisis continues, more educated Americans will suffer less job displacement risk than less educated Americans.

In the fourth column, we show the correlation with percent female at the industry level. This coefficient is stronger in the NABE sample than in the Alignable sample. As the share of women in the industry increases by ten percentage points, the share of employees working from home during the crisis increases by five percentage points. The NABE survey includes large manufacturing firms, which are generally absent from the Alignable survey. Those manufacturing firms are disproportionately male and disproportionately unable to accommodate remote work. This fact suggests that the economic impact of a longer term COVID crisis may fall particularly on less welleducated males.

In the fifth column, we show the correlation with firm size. Among these larger companies, there is no link between firm size and remote working. Large manufacturing firms again partially explain the shift between the Alignable and the NABE results. Capital-intensive firms will have the most difficulty with accommodating remote work and these are often among the largest companies in the country.

Column six includes the two industry and one firm level variable in a single regression. Only gender remains statistically significant. Column seven adds the Dingel and Neiman (2020) measure which is also insignificant controlling for these other variables. Column eight adds the share of the industry's workers who were remote before the crisis and the coefficient on that variable remains large. We only have twelve industry clusters in the NABE survey, and so for these industry level variables, we are trying to make inferences based essentially on only twelve observations. Consequently, we read little into regressions with multiple industry characteristics.

Overall Table 2 confirms that the Dingel and Neiman (2020) measure has strong predictive power, especially in the Alignable network. The coefficients in Panel (b) and Panel (c) are quite similar, which gives credence to both sets of numbers. Similarly, pre-COVID remote working is a good predictor of post-COVID remote working. Education strongly predicts remote working during the COVID crisis. 
Gender seems to have a strong impact in the larger firm, NABE, sample but not in the Alignable sample. Firm size matters in the Alignable sample but not in the NABE sample. We now turn to our measure of the productivity of remote working.

\section{The Productivity of Remote Work}

In both surveys, we asked questions about the productivity of employees who switched to remote work during the COVID-19 pandemic. In the NABE survey the question only puts productivity into broad categories. In the Alignable survey, we have a continuous measure of productivity relative to being in the office. Yet, there are good reasons to be cautious about accepting either measure without thought. First, these are estimates of at home productivity for the endogenously selected group of workers who have been allowed to work from home. Consequently, this may not tell us about productivity if the average workers from the firm were not sent home. Second, the respondents themselves may have only a limited grasp of the actual productivity impacts from working at home, especially over the long run. Third, as discussed above, we later focus on forecasts for future remote work, defined as employees who will work from home at least two days per week. During the crisis, workers who switched to working at home were likely doing so every day, and our productivity measures are likely picking up a complete absence of face-to-face interactions. The long-run productivity of employees who work remotely a few days a week may differ from those working remotely every day. As a result, our findings do not necessarily provide evidence on the productivity effects of partial remote work arrangements nor do they capture adaptations of better practices over the long-term that may make working from home more productive.

In the top panel of Table 3, we show results on assessed productivity for remote workers in the Alignable survey. The first column shows the relationship with the Dingel and Neiman (2020) measures of suitability and again the correlation is positive, but weaker than with the measure of working from home. This positive result was not a foregone conclusion, because of the endogeneity of the work-from-home decision. It was possible, that in industries where remote work is not generally suitable, that a few workers were allowed to labor remotely and that those workers were highly productive. But that does not seem to be the case. In industries where Dingel and Neiman (2020) predict that work can be done at home, entrepreneurs also believe that their at-home workers are being relatively more productive.

In the second column, we show a strong link between the number of workers who labored at home before COVID and the perceived productivity of at home workers during the COVID crisis. Again, the endogeneity of working meant that this correlation was not foreordained, but the positive coefficient is intuitive. A natural interpretation is that in some industries, working from home involves less of an economic loss and, in those same industries, there was more working from home even before the crisis.

In the third regression, we show the correlation with the average education level in the industry. As the share of the workers in the industry with a college degree increases by ten percentage points, the 
perceived productivity of at-home workers increases by .33 percentage points. This fact corroborates that working from home has been easier and more productive for better educated Americans. In the fourth column, we show that percent female in the industry is not correlated with higher productivity of at home workers.

The fifth column shows that larger firm size is associated with lower perceived productivity of at home workers, even though larger firms are more likely to have some workers laboring from home. This effect is reasonably strong. As firm size doubles, the productivity of at home workers appears to fall by almost four percent. One possible explanation for this fact is that the bigger firms had more interpersonal complementarities among their workers and these decline when the workers are physically apart. A different possibility is that larger firms require more multilateral communication, which becomes harder among remote teams (Stanton and Ghosh, 2016; Stanton and Ghosh, 2018)

The sixth column combines the two industry variables and the firm size variable. The results roughly parallel those found in Table 2a, regression (6). The coefficient on industry-level education and firm size remain significant. The coefficient on gender flips sign, but since the standard error is large, we cannot read much from that result. The more important fact is that the productivity loss from remote working seems to be lower in industries with a higher education level.

In the seventh column, we include the Dingel and Neiman (2020) variable, and it is not significant once we control for the other variables. We can conclude little from this other than a regression with 16 two-digit industries cannot meaningfully distinguish among three highly-correlated industry level variables. In the seventh regression, we control for the share of workers in the industry that worked from home pre-COVID and find again that the regression cannot distinguish between the different industry level variables.

In Panel b of Table 3, we look at the productivity of remote working in the NABE survey. There are two reasons to trust these results less than the parallel Alignable results. First, the productivity measure is a coarse category variable. Second, the respondents were economists at large companies rather than the owners of small companies. We think that it is far less plausible that the professional economist at a large company would have a good sense of the productivity of the average at-home worker in that company compared to an entrepreneur with few workers.

In this entire panel, there is only one variable with a statistically significant correlation with the productivity of remote workers: percent female in the industry. As the share of women in the industry increases by 10 percentage points, the probability that a respondents says that remote workers are actually more productive than they were before increases by 11.4 percentage points. We chose to focus on the probability that the respondent would say that remote workers were more productive than they had been, but our results are similar if we regress the probability that the remote workers were less productive than they had been on the same independent variables.

We can take little from these NABE regressions. The basic message of the Alignable results is that the variables that predict more working from home also predict less productivity loss from working at 
home, which includes industry-level education, the Dingel and Neiman (2020) measure and the share of employees in the industry who worked from home before COVID-19.

\section{Will Remote Work Continue?}

COVID-19 has killed hundreds of thousands and caused enormous economic dislocation, but it is unclear if its impact on work patterns will be temporary or permanent. One view is that work location should revert to the pre-crisis norm once the disease abates, assuming that the basic features of the economy remain unchanged. According to this view, the in-person nature of interactions within firms is beneficial, possibly for facilitating spillovers or easing communication challenges (Gaspar and Glaeser, 1998; Sandvik et al. 2020). The alternative view is that remote working will receive a permanent boost from even a temporary shock.

One reason for why the temporary shock could become permanent is that firms have now paid the fixed costs of learning how to make remote working functional, and having paid those fixed costs it is now optimal to have more remote working. A second reason for why remote working could last after COVID-19 is that firms should have been allowing more remote work before COVID-19, but they didn't either because of ignorance or because of coordination issues. ${ }^{7}$ The pandemic has provided more information and may solve the coordination problem, such that going forward firms will have far more remote work.

In both surveys the second Alignable survey and the NABE survey, respondents were asked almost identical questions about whether remote working would continue post-COVID. We focus on the overall level of expected remote working post-COVID, not on the correlations with firm or industry level characteristics. We also restrict to respondents who said that workers in their firms were working remotely during the COVID-19 crisis.

Both samples were asked about what share of workers who did not work remotely before COVID19 will do so once the crisis is over. We grouped answers into 20 percentage point bins. Twenty-one percent of the NABE sample said that they did not know what would happen after the COVID-19 crisis, and we exclude them from our table. The first column of Table 4 provides results for the Alignable sample. The second column provides results for the NABE sample that expressed an opinion about remote working after COVID-19.

The first row shows that 39 percent of the Alignable respondents think that eighty percent or more of the workers who have started working remotely during the crisis will return to their offices after the crisis. Similarly, 52 percent of the NABE think that one-fifth or less of the newly remote workers will stay remote after the crisis. For almost one-half of the sample, remote work is seen as being a

\footnotetext{
${ }^{7}$ One plausible coordination model is that if one firm deviates from a no remote working equilibrium and allows large amounts of remote working, it will attract those workers who are least committed to being part of its team.
} 
temporary expedient, but that still means that more than one-half of the sample believes that a significant number of current remote workers will stay at home after the crisis.

The second row shows that 20 percent of the Alignable survey respondents (11 percent of NABE) think that between twenty and forty percent of the newly remote workers will stay remote. The similarity between the two surveys, with 59 and 63 percent of respondents indicating that fewer than $40 \%$ of workers will remain remote, is somewhat surprising.

In the third row, 12 percent of the Alignable members and 16 percent of the NABE members expect that between 40 and 60 percent of their workers who switched to working at home will remain at home post-crisis. The last two rows find that 29 percent of Alignable entrepreneurs and 20 percent of the NABE economists think that 60 percent or more of their newly remote workers will stay remote.

Focusing on the group with the highest share of remote workers in the Alignable sample, 35\% indicated that less than 20 percent of their workforce would remain remote once the crisis ends; approximately $29 \%$ of this high-remote group indicated that more than 80 percent would remain remote at least 2 days-per-week after the crisis.

We cannot assess the accuracy of these expectations, but they do suggest a significant shift in the location of work activity even after the crisis ends. In both samples, more than 35 percent of firms think that forty percent or more of the current switch to remote working will be permanent. If true, then COVID-19 may have large long-run implications both for the location of work and for the future of U.S. real estate.

\section{Conclusion}

The COVID pandemic led to dramatic economic disruptions, as health concerns created by the virus have led people to stay at home (Alfaro et al 2020, Bartik et al 2020, Balla-Elliot et al 2020, Beland et al 2020). As our results explore, the pandemic also led to a dramatic departure in the way work is conducted - with a sharp but uneven rise in remote work. Using firm-level surveys, our results investigate remote working during the COVID-19 crisis. Although remote working has become an extremely large phenomenon during the COVID crisis, there are still many firms that do not allow any remote working.

Our analysis shows that the Dingel and Neiman (2020) classification of suitability for remote work at the industry level is an important determinant of actual remote work. Industries that are better suited to remote work also seem to experience less productivity loss when switching to remote work.

In industries with more educated workers, the level of remote working is higher and the perceived productivity loss from remote working is lower. While knowledge-intensive work done by skilled professional and business service providers can often be provided electronically, work in capital intensive factories or in hospitality and leisure tends to be harder to perform via Zoom. These results 
imply that the economic costs of the pandemic are likely to be born disproportionately by the less skilled in the absence of Federal programs that aid unemployed workers.

Finally, both of our surveys suggest that about 40 percent of both large and small firms expect that forty percent or more of their workers who switched to remote work during the crisis will stay doing remote work after the crisis. These estimates suggest that at least 16 percent of American workers will switch from professional offices to working at home at least two days per week as a result of COVID19. This would represent a dramatic and persistent shift in workplace norms around remote work, and has implications for companies, employees, and policymakers alike. An increased ability to work from home would likely influence decisions ranging from where people live to where companies locate, and has the potential to reduce demand for and reshape the nature of commercial real estate. More broadly, the shift to remote work caused by COVID is testing industry's ability to adapt, and is likely to have implications for the nature of work in the years to come. 


\section{References}

Alfaro, Laura, Ester Faia, Nora Lamersdorf, and Farzad Saidi, 2020. "Social Interactions in Pandemics: Fear, Altruism, and Reciprocity," working paper.

Balla-Elliott, Dylan, Zoe Cullen, Edward Glaeser, Michael Luca, and Christopher Stanton, 2020. "Business Reopening Decisions and Demand Forecasts During the COVID-19 Pandemic," working paper.

Bartik, Alexander, Marianne Bertrand, Zoe Cullen, Edward Glaeser, Michael Luca, and Christopher Stanton, 2020. "The Impact of COVID-19 on Small Business Outcomes and Expectations," The Proceedings of the National Academy of Sciences, 2020.

Beland, Louis, Abel Brodeur, and Taylor Wright, 2020. "The short-term economic consequences of COVID-19: exposure to disease, remote work and government response," working paper.

Bloom, Nicholas, 2014. “To Raise Productivity, Let More Employees Work from Home”, Harvard Business Review.

Bloom, Nicholas, James Liang, John Roberts, and Zhichun Jenny Ying, 2015. "Does Working from Home Work? Evidence from a Chinese Experiment”, The Quarterly Journal of Economics, Vol. 130, No. 1: 165-218.

Gaspar, Jess, and Edward L. Glaeser, 1998. "Information Technology and the Future of Cities." Journal of Urban Economics, Vol. 43, No. 1: 136-156.

Mas, Alexandre, and Amanda Pallais, 2020. "Alternative Work Arrangements." Annual Review of Economics.

Mas, Alexandre, and Amanda Pallais, 2017. "Valuing Alternative Work Arrangements." American Economic Review, Vol. 107, No. 12: 3722-3759.

Saltiel, Fernando, 2020. "Who Can Work From Home in Developing Countries?," working paper.

Sandvik, Jason, Richard Saouma, Nathan Seegert, and Christopher Stanton, 2020. "Workplace Knowledge Flows," working paper.

Stanton, Christopher, and Shikhar Ghosh, 2016. "Collage.com: Scaling a Distributed Organization." Harvard Business School Case 817-038.

Stanton, Christopher, and Shikhar Ghosh, 2018. "Collage.com: Scaling a Distributed Organization." Harvard Business School Teaching Note 818-100.

Stratton, James, 2020. "How Many Australians Can Work From Home? An Application of Dingel and Neiman (2020) to Australian Occupation Data," working paper. 
Figure 1: Probability of Reporting a Switch to Remote Work in the March/April Alignable Survey and the Share of Industry Employees Capable of Working Remotely According to the Manual Classification Scheme in Dingel and Neiman (2020)

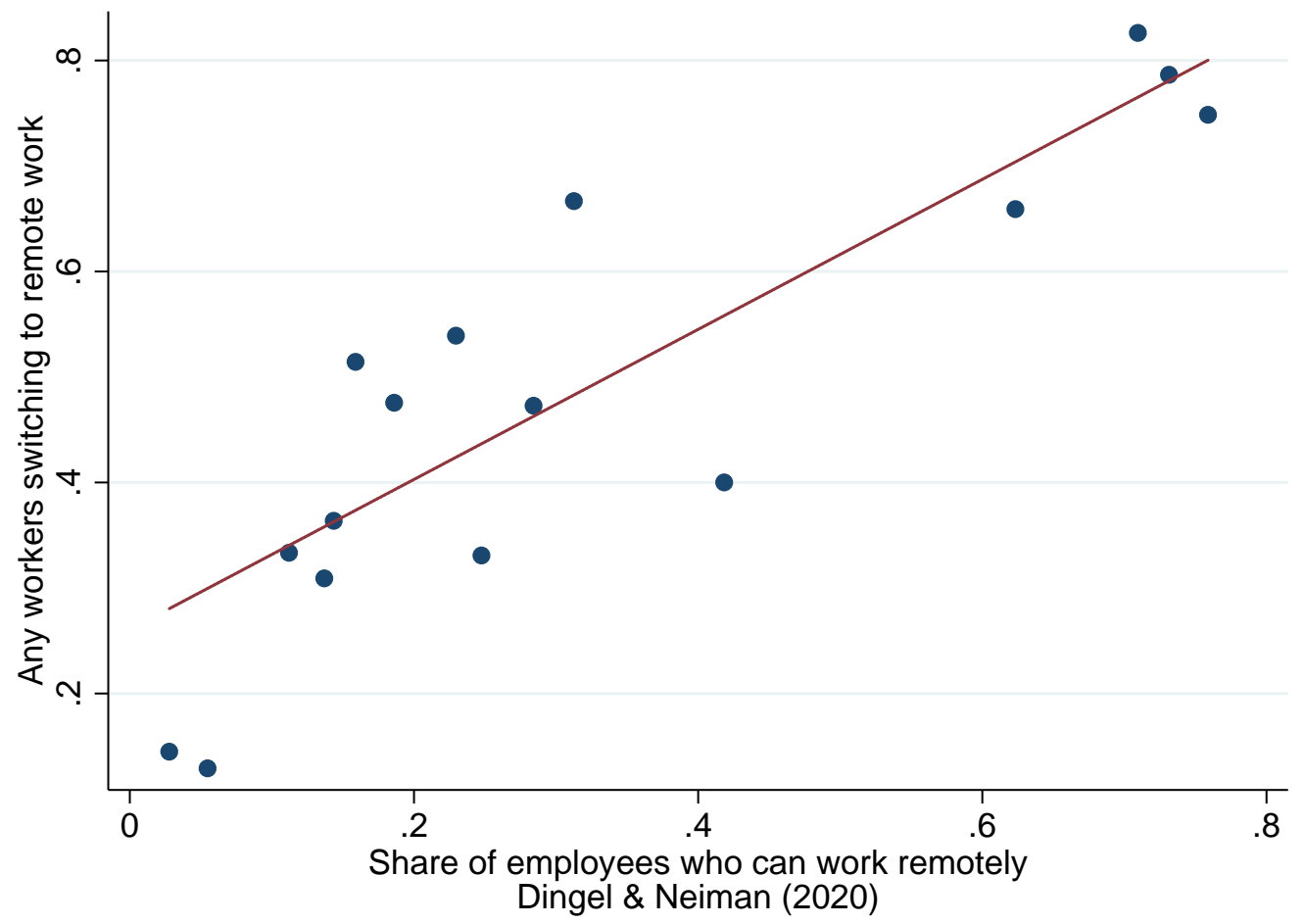


Table 1. Firm-Survey Summary Statistics

\begin{tabular}{|c|c|c|c|}
\hline & $\begin{array}{c}\text { Alignable (March/April) } \\
\text { (1) }\end{array}$ & $\begin{array}{c}\text { Alignable (May) } \\
(2)\end{array}$ & $\begin{array}{l}\text { NABE } \\
(3) \\
\end{array}$ \\
\hline Number of Pre-COVID Employees & 14 & 27 & 532 \\
\hline \% Change in Emp from Jan to Survey Date, 2020 & -0.159 & -0.074 & - \\
\hline Share "Severely Impacted" by COVID-19 & - & 0.510 & 0.329 \\
\hline Any Workers Switching to Remote During COVID & 0.451 & - & - \\
\hline Share of Workers Switching to Remote During COVID & - & 0.227 & - \\
\hline Share of Workers Working Remotely (during COVID) & - & - & 0.789 \\
\hline \multicolumn{4}{|l|}{ Share of Workers Able to Work Remotely (Manual } \\
\hline Version of Dingel and Neiman (2020)) & 0.267 & 0.304 & 0.594 \\
\hline \multicolumn{4}{|l|}{ Share of Workers Able to Work Remotely (O-NET } \\
\hline version of Dingel and Neiman (2020)) & 0.314 & 0.350 & 0.643 \\
\hline $\mathrm{N}$ & 1,770 & 908 & 70 \\
\hline
\end{tabular}

Notes: Summary statistics for the three different surveys. The survey in column 1 was conducted in late March and early April, as described in Bartik et al. (2020). The survey in column 2 was conducted by Alignable beginning May 23, 2020. The survey in column 3 was conducted by NABE in April. Column 2 includes data from 5 firms with more than 500 employees. Excluding these firms reduces average employment to 19. 
Table 2. Relationship between working remotely and industry characteristics

\begin{tabular}{|c|c|c|c|c|c|c|c|c|}
\hline & (1) & (2) & (3) & (4) & (5) & (6) & (7) & (8) \\
\hline \multicolumn{9}{|c|}{ Panel A. March/April Alignable Survey (Outcome: Any employees switching to remote work (currently, during COVID)) } \\
\hline \multirow{2}{*}{ Share capable of remote work } & 0.711 & & & & & & 0.263 & \\
\hline & $(0.073)$ & & & & & & $(0.241)$ & \\
\hline \multirow[t]{2}{*}{ Share of industry working from home (ACS) } & & 4.100 & & & & & - & -1.323 \\
\hline & & $(0.907)$ & & & & & - & (1.129) \\
\hline \multirow[t]{2}{*}{ Share of industry with BA+ degree (ACS) } & & & 0.942 & & & 1.139 & 0.774 & 1.359 \\
\hline & & & $(0.135)$ & & & $(0.194)$ & $(0.411)$ & $(0.219)$ \\
\hline \multirow[t]{2}{*}{ Share of industry female (ACS) } & & & & 0.165 & & -0.257 & -0.161 & -0.345 \\
\hline & & & & $(0.115)$ & & $(0.085)$ & $(0.148)$ & $(0.089)$ \\
\hline \multirow[t]{2}{*}{ Log firm employment } & & & & & 0.049 & 0.075 & 0.076 & 0.074 \\
\hline & & & & & $(0.024)$ & $(0.017)$ & $(0.016)$ & $(0.017)$ \\
\hline $\mathrm{N}$ & 1,770 & 1,770 & 1,770 & 1,770 & 1,770 & 1,770 & 1,770 & 1,770 \\
\hline Number of two-digit industries & 16 & 16 & 16 & 16 & 16 & 16 & 16 & 16 \\
\hline R-squared & 0.110 & 0.064 & 0.109 & 0.005 & 0.010 & 0.139 & 0.141 & 0.141 \\
\hline \multicolumn{9}{|c|}{ Panel B. May Alignable Survey (Outcome: Share of workers switching to remote work during COVID-19) } \\
\hline \multirow[t]{2}{*}{ Share capable of remote work } & 0.279 & & & & & & 0.253 & \\
\hline & $(0.058)$ & & & & & & $(0.129)$ & \\
\hline \multirow[t]{2}{*}{ Share of industry working from home (ACS) } & & 1.355 & & & & & - & -0.361 \\
\hline & & $(0.455)$ & & & & & - & $(0.624)$ \\
\hline \multirow[t]{2}{*}{ Share of industry with BA+ degree (ACS) } & & & 0.394 & & & 0.389 & 0.044 & 0.442 \\
\hline & & & $(0.097)$ & & & $(0.101)$ & $(0.218)$ & $(0.124)$ \\
\hline \multirow[t]{2}{*}{ Share of industry female (ACS) } & & & & 0.166 & & 0.041 & 0.125 & 0.017 \\
\hline & & & & $(0.086)$ & & $(0.062)$ & $(0.069)$ & $(0.061)$ \\
\hline \multirow[t]{2}{*}{ Log firm employment } & & & & & 0.001 & 0.005 & 0.007 & 0.005 \\
\hline & & & & & $(0.009)$ & $(0.008)$ & $(0.008)$ & $(0.008)$ \\
\hline $\mathrm{N}$ & 908 & 908 & 908 & 908 & 893 & 893 & 893 & 893 \\
\hline Number of two-digit industries & 18 & 18 & 18 & 18 & 18 & 18 & 18 & 18 \\
\hline R-squared & 0.067 & 0.026 & 0.069 & 0.010 & 0.000 & 0.071 & 0.078 & 0.072 \\
\hline \multicolumn{9}{|c|}{ Panel C. NABE Survey (Outcome: Share of workers working remotely during COVID-19) } \\
\hline \multirow[t]{2}{*}{ Share capable of remote work } & 0.283 & & & & & & 0.037 & \\
\hline & $(0.149)$ & & & & & & $(0.322)$ & \\
\hline \multirow[t]{2}{*}{ Share of industry working from home (ACS) } & & 1.642 & & & & & - & 0.914 \\
\hline & & $(0.806)$ & & & & & - & $(0.522)$ \\
\hline \multirow[t]{2}{*}{ Share of industry with BA+ degree (ACS) } & & & 0.372 & & & 0.321 & 0.274 & 0.167 \\
\hline & & & (0.199) & & & $(0.180)$ & $(0.366)$ & $(0.214)$ \\
\hline \multirow[t]{2}{*}{ Share of industry female (ACS) } & & & & 0.501 & & 0.426 & 0.418 & 0.458 \\
\hline & & & & $(0.223)$ & & $(0.183)$ & $(0.224)$ & $(0.177)$ \\
\hline \multirow[t]{2}{*}{ Log firm employment } & & & & & -0.011 & -0.003 & -0.003 & -0.002 \\
\hline & & & & & $(0.010)$ & $(0.009)$ & $(0.009)$ & $(0.008)$ \\
\hline $\mathrm{N}$ & 70 & 70 & 70 & 70 & 70 & 70 & 70 & 70 \\
\hline Number of two-digit industries & 12 & 12 & 12 & 12 & 12 & 12 & 12 & 12 \\
\hline R-squared & 0.087 & 0.070 & 0.084 & 0.057 & 0.020 & 0.126 & 0.126 & 0.132 \\
\hline
\end{tabular}

Notes: Standard errors clustered at the two-digit industry level shown in parentheses. The share capable of working remotely is the Dingel and Neiman (2020) measure that includes manual classification. The share of industry working from home, share of industry with a BA or higher degree, and the share of industry female are computed using 2 digit NAICS industries in the 2016-2017 American Community Survey. In Panels B and C, respondents chose intervals $(0-20 \%, 20-40 \%, 40-60 \%, 60-80 \%, 80-100 \%)$ and we convert these to numeric measures using the midpoint of the intervals. 
Table 3. Relationship between remote worker productivity and industry characteristics

(1) (2) (3) (4)

\begin{tabular}{llll}
$(4)$ & $(5)$ & $(6)$ & $(7)$ \\
\hline
\end{tabular}

Panel A. March/April Alignable Survey (Outcome: Remote worker productivity relative to non-remote worker productivity)

\begin{tabular}{|c|c|c|c|c|c|c|c|c|}
\hline Share capable of remote work & $\begin{array}{c}0.237 \\
(0.043)\end{array}$ & & & & & & $\begin{array}{c}0.040 \\
(0.149)\end{array}$ & \\
\hline Share of industry working from home (ACS) & & $\begin{array}{c}1.834 \\
(0.426)\end{array}$ & & & & & - & $\begin{array}{c}0.860 \\
(0.800)\end{array}$ \\
\hline Share of industry with BA+ degree (ACS) & & & $\begin{array}{c}0.328 \\
(0.075)\end{array}$ & & & $\begin{array}{c}0.337 \\
(0.083)\end{array}$ & $\begin{array}{c}0.278 \\
(0.262)\end{array}$ & $\begin{array}{c}0.188 \\
(0.185)\end{array}$ \\
\hline Share of industry female (ACS) & & & & $\begin{array}{c}0.070 \\
(0.050)\end{array}$ & & $\begin{array}{l}-0.084 \\
(0.070)\end{array}$ & $\begin{array}{l}-0.069 \\
(0.104)\end{array}$ & $\begin{array}{l}-0.023 \\
(0.110)\end{array}$ \\
\hline Log firm employment & & & & & $\begin{array}{l}-0.039 \\
(0.008)\end{array}$ & $\begin{array}{l}-0.029 \\
(0.007)\end{array}$ & $\begin{array}{l}-0.029 \\
(0.008)\end{array}$ & $\begin{array}{l}-0.029 \\
(0.007)\end{array}$ \\
\hline $\mathrm{N}$ & 653 & 653 & 653 & 653 & 653 & 653 & 653 & 653 \\
\hline Two-digit industries & 16 & 16 & 16 & 16 & 16 & 16 & 16 & 16 \\
\hline R-squared & 0.022 & 0.021 & 0.021 & 0.001 & 0.011 & 0.028 & 0.029 & 0.030 \\
\hline \multicolumn{9}{|c|}{ Panel B. April NABE Survey (Outcome: Indicator for firm saying that remote workers have above average productivity) } \\
\hline Share capable of remote work & $\begin{array}{l}-0.206 \\
(0.276)\end{array}$ & & & & & & $\begin{array}{l}-0.144 \\
(0.576)\end{array}$ & \\
\hline Share of industry working from home (ACS) & & $\begin{array}{l}-2.489 \\
(1.912)\end{array}$ & & & & & - & $\begin{array}{l}-2.686 \\
(1.999)\end{array}$ \\
\hline Share of industry with $B A+$ degree (ACS) & & & $\begin{array}{l}-0.333 \\
(0.388)\end{array}$ & & & $\begin{array}{l}-0.569 \\
(0.177)\end{array}$ & $\begin{array}{l}-0.386 \\
(0.747)\end{array}$ & $\begin{array}{l}-0.115 \\
(0.429)\end{array}$ \\
\hline Share of industry female (ACS) & & & & $\begin{array}{c}1.140 \\
(0.393)\end{array}$ & & $\begin{array}{c}1.235 \\
(0.331)\end{array}$ & $\begin{array}{l}1.262 \\
(0.338)\end{array}$ & $\begin{array}{c}1.150 \\
(0.393)\end{array}$ \\
\hline Log firm employment & & & & & $\begin{array}{l}-0.012 \\
(0.021)\end{array}$ & $\begin{array}{l}-0.021 \\
(0.014)\end{array}$ & $\begin{array}{l}-0.021 \\
(0.014)\end{array}$ & $\begin{array}{l}-0.022 \\
(0.014)\end{array}$ \\
\hline $\mathrm{N}$ & 65 & 65 & 65 & 65 & 65 & 65 & 65 & 65 \\
\hline Two-digit industries & 12 & 12 & 12 & 12 & 12 & 12 & 12 & 12 \\
\hline R-squared & 0.011 & 0.037 & 0.015 & 0.071 & 0.005 & 0.112 & 0.112 & 0.125 \\
\hline
\end{tabular}

Notes: Standard errors clusteres at the two-digit industry level shown in parentheses. ACS characteristics are defined based on the mean of workers' two-digit industries in 2016 and 2017. The sample is restricted to firms that answered the question regarding the producitivty of their remote workers (i.e. those that had remote workers). 
Table 4. Share of workers who switched to remote worker during COVID-19 that will continue working remotely after COVID

\begin{tabular}{lcc}
\hline & $\begin{array}{c}\text { Alignable (May) } \\
(1)\end{array}$ & NABE \\
& $(2)$ \\
\hline \hline $0-20 \%$ & 0.39 & 0.52 \\
$20-40 \%$ & 0.20 & 0.11 \\
$40-60 \%$ & 0.12 & 0.16 \\
$60-80 \%$ & 0.12 & 0.07 \\
$80-100 \%$ & 0.17 & 0.13 \\
& & \\
$\mathrm{~N}$ & 203 & 61 \\
\hline
\end{tabular}

Note: The sample for the Alignable question was restricted to those who had more than $20 \%$ of their workforce in remote positions. The NABE sample excludes those who "do not know" the answer to the question. 


\section{Online Appendix for \\ "What Jobs are Being Done at Home during the Covid-19 Crisis? \\ Evidence from Firm-Level Surveys"}

Alexander W. Bartik, Zoe Cullen, Edward L. Glaeser, Michael Luca, and Christopher Stanton

This online appendix discusses benchmarking of the surveys compared to the 2017 US Census of Businesses. Because Alignable is a membership network for small businesses, we compare Alignable responses to firms with fewer than 500 employees in the Census for 2017, the last year of available data.

Table A1 displays the share of responses by NAICS 2-digit industry for both Alignable surveys and compares response frequency to the underlying distribution of businesses in the Census. Figures A1 and A2 report the share of responses by State for the Census and the Alignable March/April and Alignable May surveys, respectively. 
Figure A1: Census versus Survey Shares by State in the March/April Alignable Survey

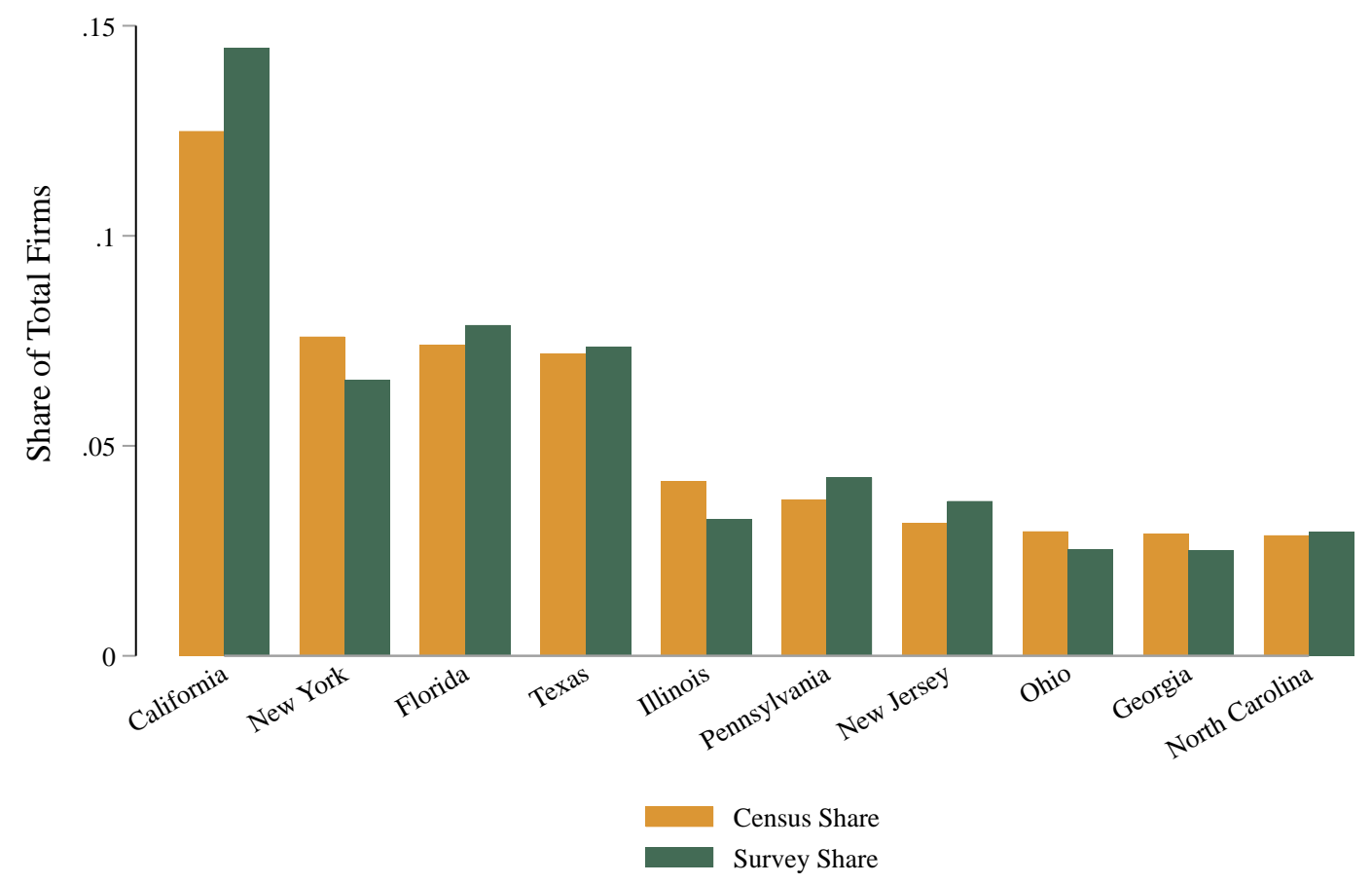


Figure A2: Census versus Survey Shares by State in the May Alignable Survey

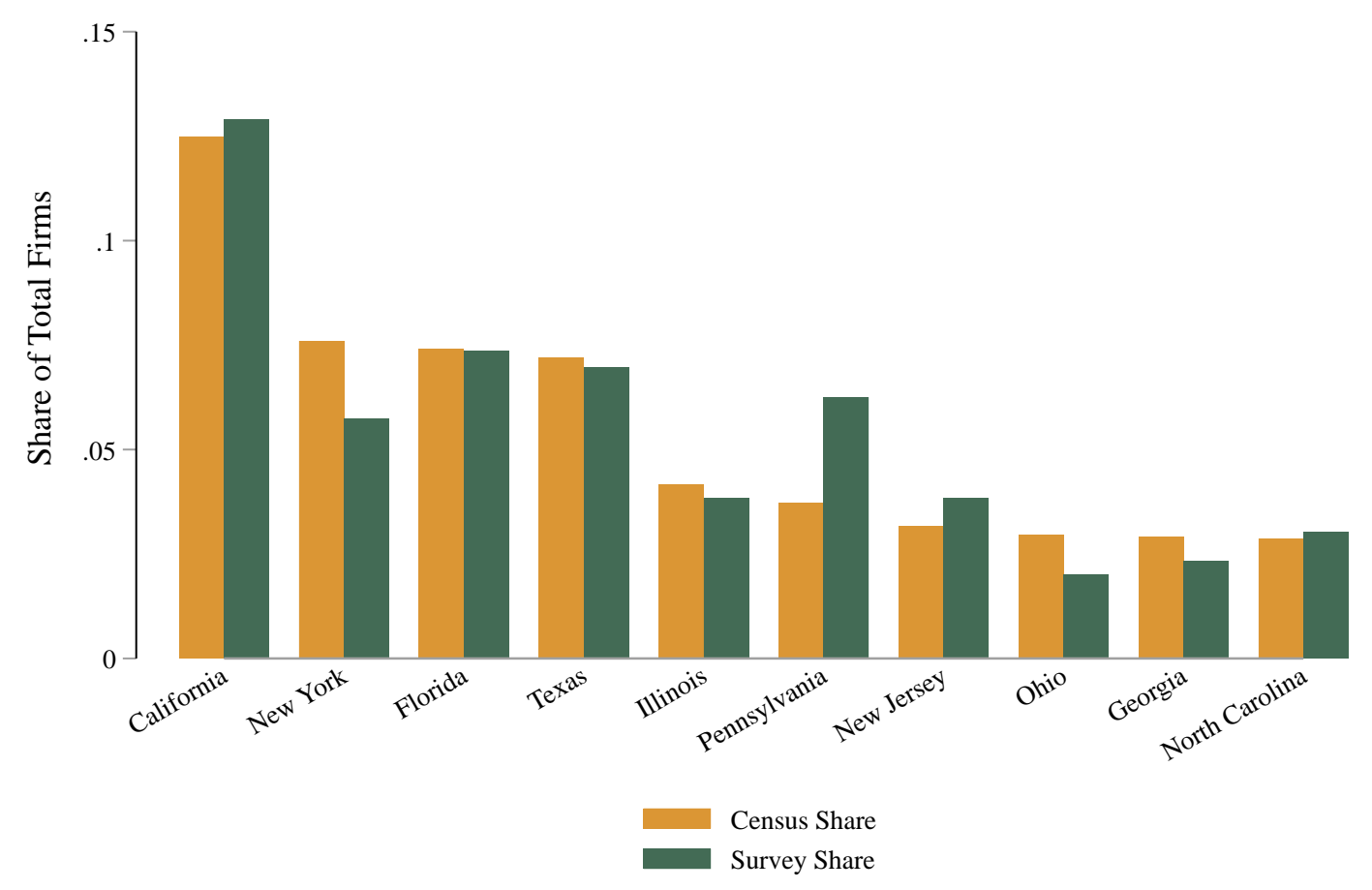


Census Share Alignable March/April Alignable May

Agri, Forestry, Fishing and Hunting

$0.4 \%$

$0.1 \%$

$11.6 \%$

Construction

Manufacturing

Wholesale Trade

Retail Trade

Transportation and Warehousing

Information

Finance and Insurance

Real Estate Rental and Leasing

Prof, Scientific, and Technical Serv

Manag of Comps and Enterprises

Admin, Support, Waste and Remed Serv

Educational Services

Health Care and Social Assist

Arts, Entert, and Recreation

Accommodation and Food Services

Other Services (expt Public Admin)
$4.1 \%$

$4.9 \%$

$10.7 \%$

$3.0 \%$

$1.3 \%$

$3.9 \%$

$5.1 \%$

$13.4 \%$

$0.3 \%$

$5.7 \%$

$1.5 \%$

$10.8 \%$

$2.1 \%$

$8.9 \%$

$11.5 \%$
$1.3 \%$

$0.1 \%$

$11.8 \%$

$4.0 \%$

$0.1 \%$

$15.9 \%$

$2.4 \%$

$2.8 \%$

$4.8 \%$

$4.4 \%$

$9.4 \%$

$0.0 \%$

$2.1 \%$

$2.4 \%$

$12.4 \%$

$9.1 \%$

$8.0 \%$

$9.0 \%$
$1.7 \%$

$0.4 \%$

$4.8 \%$

$7.4 \%$

$2.3 \%$

$15.2 \%$

$0.9 \%$

$2.2 \%$

$7.1 \%$

$1.7 \%$

$10.3 \%$

$0.0 \%$

$5.2 \%$

$2.9 \%$

$9.5 \%$

$3.4 \%$

$9.2 \%$

$14.0 \%$

Notes: The Census share comes from the 2017 Census of US Businesses, derived from the County Business Patterns. The Alignable shares include only firms with non-missing industry information, the restriction used throughout the paper. 